\title{
Resenha da tradução brasileira de Escola Francesa de Geografia: uma abordagem contextual de Vicent Berdoulay
}

\author{
Rodrigo Corrêa Teixeira \\ Prof. do Programa de Pós-Graduação em Geografia \\ Tratamento da Informação Espacial \\ PUC Minas, Brasil \\ rteixeira@pucminas.br
}

BERDOULAY V. Escola francesa de geografia: uma abordagem contextual. Tradução de Oswaldo Bueno Amorim Filho. São Paulo: Perspectiva, 2017. 280p.

\section{INTRODUÇÃO (sobre a tradução e a importância da obra)}

A obra “A Escola Francesa de Geografia: uma abordagem contextual”, já clássica no ambiente acadêmico francófono, apresenta uma interpretação bastante original da gênese e da consolidação dessa corrente epistemológica no período compreendido entre os anos de 1870 a 1914.

Inicialmente o texto é a tese de doutorado (Societal context and the emergence of the French school of geography - 1870-1914), defendida no ano de 1974 por Vincent Berdoulay, na influente Universidade da Califórnia, em Berkeley, sob a orientação de David Hooson (1926 2008), que se tornou notável na especialidade de geografia soviética e russa.

A obra foi publicada, pela primeira vez em 1981, na França. A ótima acolhida do título e as pesquisas continuadas em torno do tema pelo autor, o fizeram atualizá-la, gerando duas reedições da obra, nos anos de 1995 e 2008.

Recentemente, esta última edição foi traduzida para o português por Oswaldo Bueno Amorim Filho. Vinculado ao Programa de Pós-graduação em Geografia - Tratamento da Informação Espacial da PUC-Minas), é um dos mais prestigiados geógrafos brasileiros, sendo autor de uma vasta obra, sob a forma de livros e artigos no transcurso das últimas cinco décadas ${ }^{1}$. Amorim Filho tem vasta experiência na tradução de textos clássicos do pensamento geográfico, com destaque para Geografia e Geógrafos: a geografia humana anglo-americana desde 1945 de R.J. Johnston (1986). Em suas atividades como docente e pesquisador, sobretudo nas áreas de epistemologia da geografia, geopolítica, geografia humanista-cultural e Geografia Urbana, com destaque para as cidades médias, empreendeu um conjunto extenso de traduções para formação e

\footnotetext{
${ }^{1}$ Possui graduação em Bacharelado e Licenciatura em Geografia pela Universidade Federal de Minas Gerais (1970) e Doutorado em Geografia - Université de Bordeaux III (1973); é Professor Titular aposentado da UFMG; entre 2004 e 2019, foi docente do Programa de Pós-Graduação em Geografia - Tratamento da Informação Espacial da PUC Minas.
} 
qualificação de novos profissionais. Essses textos traduzidos estão inéditos, no entanto fizeram parte da trajetória geógrafica de centenas de geografas e geógrafos. ${ }^{2}$

Berdoulay propõe uma abordagem metodológica inovadora, que ele denomina de contextual, proporcionando uma leitura interseccional sobre os fatores internos e externos que esteiam o devir do pensamento científico. Berdoulay, em artigo publicado originalmente em 1981 (2003), sugere que na História do Pensamento Geográfico, como em outras áreas do saber, são comuns os debates existentes entre visões internalistas e externalistas de construção do conhecimento. Para os internalistas é necessário dedicar-se mais ao próprio conteúdo do conhecimento científico, enquanto as preocupações externalistas voltam-se, sobretudo, para a investigação das relações que o conteúdo científico possui com os processos sociais.

Trata-se de propor novas formas de se conceber o discurso historiográfico. Essa perspectiva considera as descontinuidades das tendências científicas, a interdependência das ciências e as condições para a realização das pesquisas, tanto internas da própria ciência quanto as de âmbito mais macro, como as relações político-econômicas da sociedade. Essas relações seriam determinantes para a totalidade do fazer científico, no entanto, não seriam deterministas. Esta perspectiva permite articular elementos históricos, epistemológicos, conceituais, econômicos e sociopolíticos, como também fundamentou o repúdio à linearidade da interpretação finalista que acaba por atribuir superioridade intelectual a determinadas perspectivas científicas, principalmente aquelas que conseguiram posteridade no âmbito acadêmico-social.

A chamada "Escola Francesa de Geografia" consolidou-se no contexto da década de 1870, durante a configuração da Terceira República e da vontade positivista de trazer o progresso da revolução industrial e científica aos países que ainda não tinham se beneficiado dela. A Geografia participa com outras ciências pela "grandeza da França", se mesmo com uma adesão ao movimento colonial, há um contraponto feito por certos geógrafos denunciando os excessos da exploração. A Geografia ocupa um lugar importante no ambiente do ensino superior. Ela é introduzida em todos os níveis de ensino no transcurso da década de 1880. Além disso, esse contexto emergente da Geografia favorece as grandes editoras (Armand Colin, sobretudo) e mecenas influentes, tal como o banqueiro Albert Kahn (1860 - 1940), e encontra um interesse muito intenso por parte dos cidadãos em geral. A forte personalidade de Paul Vidal de La Blache conduz à imposição e "concerto" das tendências rivais que se confrontavam no seio da Escola Francesa de Geografia e para adquirir mundialmente uma notoriedade considerável, que vai ser hegemônica até a década de 1950.

\footnotetext{
${ }^{2} \mathrm{O}$ resenhista teve a honra e satisfação de ser aluno e colaborar em pesquisas com o tradutor.
} 


\section{VINCENT BARDOULAY: NOTA BIOGRÁFICA}

O Prof. Vincent Berdoulay nasceu em Nemours (hoje Ghazaouet) no noroeste da Argélia, em 1947. Realizou seus estudos na Université de Bordeaux, onde obtuve a Iicenciatura em História e Geografia (1967) e o mestrado en Geografía (1970). Em 1974 alcançou o doutorado na University of California (Berkeley). Foi pesquisador visitante, em pós-doutoramento na Ohio State University (1974 - 1975), professor na l'Université d'Ottawa (1975 - 1989), e também ensinou em outras renomadas instituições, tais como: L'Université de Sherbrooke, l'Université de Montréal, University of California (Berkeley), Universidade Estadual de Campinas (UNICAMP) e Universidade Federal do Rio de Janeiro (UFRJ). É membro do Comité d'orientation da revista "Cahiers de Géographie du Québec" - l'Université Laval (1983-89) e membro do Conselho Consultivo da Terra Brasilis (Rede Brasileira de História da Geografia e Geografia Histórica (2000 - presente). É membro do Laboratoire Passages da Université de Pau et des Pays de l'Adour (departamento francês dos Pirineus Atlânticos). Seus principais temas de intereresses são, do ponto de vista das investigações e publicações, a história e a epistemologia da Geografia, a Geografía Social e Cultural, os problemas de percepção e representação do meio ambiente, o desenvolvimento sustentável e adapatação às mudamças climáticas, a ecologia urbana, o sujeito, dentre outras predileções, todas temáticas tendo como fio condutor a perspectiva lablacheana (ou como ele prefere, "vidaliana").

\section{ESTRUTURA DA OBRA}

No Prefácio à edição brasileira (p. IX - XII), Eduardo Marandola Junior ${ }^{3}$, assinala o significado da tradução da obra tanto para a ontologia e epistemologia geográfica quanto para a história do pensamento social brasileiro e da formação sociocultural de nosso território.

$\mathrm{Na}$ Introdução (p. XIII - XXIV) situa-se o leitor na compreensão do pensamento geográfico na sociedade francesa, desde as origens da Terceira República até às vésperas da Primeira Guerra Mundial, expondo os fundamentos históricos e epistemológicos.

No capítulo 1, O Desafio Alemão (p. 1- 29), demonstra que o fato da Geografia ter se desenvolvido mais cedo na Alemanha tornou-se um elemento psicológico de expressiva importância na cultura geográfica francesa, após a derrota de 1870-1871. Ligado intimamente ao ressurgimento do nacionalismo, a postura por parte dos vidalianos, em fins da década de 1890, se traduziu na preferência pela expressão "geografia humana", ao invés de "antropogeografia" e, em 1910, Jean Brunhes publicou o primeiro manual francês dessa nova disciplina. Os jovens vidalianos constituíram-se numa escola francesa buscando uma reputação internacional.

\footnotetext{
${ }^{3}$ Professor da Faculdade de Ciências Aplicadas (FCA) da Unicamp (Campus de Limeira) e editor da revista eletrônica Geograficidade, do Grupo de Pesquisa Geografia Humanista Cultural (UFF/CNPq).
} 
O grupo vidaliano entrou num processo de diferenciação em relação à Alemanha, tendo como um contexto marcante a perda da Alsácia-Lorena, encorajando as reflexões sobre a nação e a unidade nacional. Procurou-se demonstrar que o pertencimento de um território a uma nação devia repousar na vontade e nas preferências dos residentes deste território, e não em suas características linguísticas ou étnicas. Vidal tentou demonstrar que a França do Leste, incluindo a Alsácia-Lorena, formava uma só unidade territorial, configurada por forças culturais e econômicas, a despeito de sua dualidade linguística e das limitações do meio. Vidal tratava à Alsácia-Lorena como uma parte integrante da França, num frontal ataque ao expansionismo alemão, sobretudo pela desconsideração em relação à geografia histórica dos povos.

Conforme apresenta o capítulo 2, O Movimento Colonial (p. 31- 64), os geógrafos franceses não somente foram influenciados pela expansão colonial como também a influenciaram. Ao mesmo tempo em que pregava que a ciência deveria ser objetiva e neutra, uma parte importante da Escola Francesa de Geografia comprometia-se com o Estado, defendendo o direito de o mesmo possuir colônias na América, na África e na Ásia.

Durante a Terceira República (1870-1914), a França era uma potência imperial, que rivalizava com o Reino Unido e a Alemanha principalmente, pelo controle colonial nos demais continentes. A França se autodeclarava uma civilização "superior”, com o dereito de conquistar e civilizar os povos "inferiores". Nesta ação imperialista, o conhecimento científico em geral, e em particular a Geografia, teve uma importância fundamental. A atividade de dominar, desenvolver e explorar as possessões territoriais de "ultramar" requeria conhecimentos práticos, de técnicas de coleta de informação e de métodos para conhecer sobre outras regiões e outras populações. A Geografia esteve, por décadas, ligada aos interesses e necessidades do imperialismo, e seus desenvolvimentos acadêmicos e científicos trataram de responder o melhor possível a tais demandas.

A geografia colonial, além de atender as necessidades do mundo dos negócios (inventários dos recursos e mercados), instalou-se cumpriu demandas da administração colonial francesa (conhecimento dos lugares e povos que deveriam ser organizados sob a dominação francesa).

O capítulo 3, O Ensino (p. 65 - 99), traz a implantação da Terceira República que assegurou as estruturas para o ensino de Geogarfai em todos os níveis. As relações que existem entre o ensino, a política e as histórias social e intelectual forma profundas. Vidal ocupou a melhor posição estratégica para promover o ensino de Geografia no contexto republicano.

O capítulo 4, A Busca de uma Nova Ordem Social (p. 101 - 134), considerando que uma espécie de aliança foi instituída, pelo menos verbalmente, entre a ciência e a República. Esse comtexto trouxe a defesa do idealismo filosófico, com três valores exaltados: o trabalho, o método 
empírico e a associação. Com esses valores no espirito, desenvolvia-se a abordagem das relações do homem com a terra.

No Capítulo 5, Os Círculos de Afinidade: formação e alcance (p.135 - 178), quando em 1874 uma decisão governamental aponta para a criação de uma cadeira de geografia em todas as universidades do Estado francês, identificaram-se oito potenciais grupos candidatos a exercer a posse das cadeiras universitárias na França, que vinham à tona no final do século XIX (tendo em vista a reforma educacional do Segundo Império - de 1852 a 1870):

Tabela 1 - Os "Círculos de afinidades"4 do pensamento geográfico francês - entre 1870 e 1914.

\begin{tabular}{|c|c|c|}
\hline "Círculo de afinidades" & Liderança & Observações \\
\hline $\begin{array}{l}1 \text { - Os autores do Inventário } \\
\text { Terrestre - patrocinados pelas } \\
\text { Sociedades de Geografia } \\
\text { (BERDOULAY, 2017, p. } \\
\text { 149-151) }\end{array}$ & $\begin{array}{l}\text { Sociedade de Geografia de Paris, } \\
\text { surgida em } 1821\end{array}$ & $\begin{array}{l}\text { Nessa época multiplicou-se o número dessas } \\
\text { associações científicas por toda a Europa; todas } \\
\text { tinham como objetivo principal manter, entre } \\
\text { seus associados, um conhecimento } \\
\text { do mundo, o mais atualizado possível, e assim } \\
\text { poder contribuir para o progresso de cada país; } \\
\text { para tal, eles acolhiam um número significativo } \\
\text { de narrativas de viagens e até mesmo estudos } \\
\text { realizados por amadores curiosos; suas reuniões } \\
\text { e encontros anuais correspondiam à parte mais } \\
\text { interessante do trabalho dos que se } \\
\text { autodominavam naturalistas, etnólogos e } \\
\text { geógrafos; além de membros dessas Sociedades } \\
\text { Científicas, alguns desses homens eram } \\
\text { representantes do poder público, professores das } \\
\text { escolas politécnicas, observatórios, museus, } \\
\text { faculdades e alguns funcionários da } \\
\text { administração francesa, sobretudo do } \\
\text { "Subsecretariado de Estado para as Colônias", } \\
\text { (alternadamente vinculado ao Ministério do } \\
\text { Comércio e ao Ministério da Marinha); } \\
\text { destacou-se a "descoberta” das regiões } \\
\text { subsaarianas da África. }\end{array}$ \\
\hline $\begin{array}{l}2 \text { - Os Especialistas da } \\
\text { Geografia Histórica - de estilo } \\
\text { antigo estilo, impulsionada } \\
\text { por Himly (BERDOULAY, } \\
2017 \text {, p. } 151-155)\end{array}$ & $\begin{array}{l}\text { Auguste Louis Himly (1823 - } \\
\text { 1906), professor de História e } \\
\text { Geografia }\end{array}$ & $\begin{array}{l}\text { Propunham uma transposição de uma } \\
\text { metodologia minuciuosa de exame de } \\
\text { documentação arquivistica, a fim de compor } \\
\text { uma uma forma de História Regional. }\end{array}$ \\
\hline $\begin{array}{l}3 \text { - O Círculo de Afinidade de } \\
\text { Drapeyron - que incitava uma } \\
\text { geografia prática ligada aos } \\
\text { interesses coloniais } \\
\text { (BERDOULAY, 2017, p. } \\
\text { 155-159) }\end{array}$ & $\begin{array}{l}\text { Ludovic Drapeyron (1839- } \\
\text { 1901), geógrafo e historiador }\end{array}$ & $\begin{array}{l}\text { A partir da Revue de géographie et de la Société } \\
\text { de topographie (criada em 1876) se fez uma } \\
\text { defesa da introdução da ciência topográfica em } \\
\text { todas as regiões da França, sobretudo, } \\
\text { focalizando os professores; os dois pilares são } \\
\text { pedagogia e cartografia. }\end{array}$ \\
\hline $\begin{array}{l}\text { 4 - O Círculo de Afinidade de } \\
\text { Levasseur - A geografia } \\
\text { econômica e estatística de } \\
\text { Emile Levasseur (BER- } \\
\text { DOULAY, 2017, p. } 159-165 \text { ) }\end{array}$ & $\begin{array}{l}\text { Émile Levasseur (1828-1911), } \\
\text { economista e estadista }\end{array}$ & $\begin{array}{l}\text { Levasseur institucionalizou o ensino da } \\
\text { Geografia no sistema educacional francês, como } \\
\text { crítico das explicações deterministas sobre as } \\
\text { relações homem-natureza. }\end{array}$ \\
\hline
\end{tabular}

\footnotetext{
${ }^{4}$ Um grupo de cientistas busca legitimar suas ideias e se tornar hegemônico (procurando continuidade nessa posição) tanto pela força intelectual, propriamente dita, quanto pela nucleação em torno de um conjunto de conhecimentos; a organização, por meio de hierarquias formadas, a eleição de intelectuais que se esforcem para a institucionalização de sua perspectiva e a elaboração de alianças com grupos sociais que constituem influências estruturadoras; assim as estratégias dos geógrafos e acadêmicos são tanto epistemológicas quanto sociais (BERDOULAY, 2017).
} 


\begin{tabular}{|c|c|c|}
\hline $\begin{array}{l}5 \text { - O Círculo de "La Science } \\
\text { Sociale" - grupo da Nova } \\
\text { Ordem Social - discípulos de } \\
\text { Le Play que se dedicavam à } \\
\text { relação das famílias e dos } \\
\text { grupos com o meio } \\
\text { (BERDOULAY, 2017, p. } \\
\text { 165-167) }\end{array}$ & Frederic Le Play (1806-1882) & $\begin{array}{l}\text { Na França, Le Play foi o iniciador dos métodos } \\
\text { "monográficos", para estudar empiricamente as } \\
\text { relações entre uma sociedade e seu entorno } \\
\text { geográfico imediato. }\end{array}$ \\
\hline $\begin{array}{l}\text { 6 - Os Geógrafos em Posição } \\
\text { Marginal - como Elisée } \\
\text { Reclus (BERDOULAY, } \\
\text { 2017, p. 167-169) }\end{array}$ & $\begin{array}{l}\text { Elisée Reclus (1830 - 1905) } \\
\text { geógrafo, mas, antes de tudo, um } \\
\text { anarquista; uma liderança } \\
\text { inspiradora }\end{array}$ & $\begin{array}{l}\text { Muitos outros aspectos do pensamento de } \\
\text { Reclus estavam ligados a sua concepção do } \\
\text { indivíduo, com sua valorização da educação, a } \\
\text { ajuda mútua, a responsabilidade moral e } \\
\text { ecológica; as ideias libertárias, sobretudo } \\
\text { anarquistas, serviram de base para a elaboração } \\
\text { dos escritos considerados como marginais, por } \\
\text { se oporem claramente ao status quo. }\end{array}$ \\
\hline $\begin{array}{l}7 \text { - Os Morfólogos Sociais - } \\
\text { de Durkheim e seus } \\
\text { discípulos, que pleiteavam } \\
\text { estudar o substrato material } \\
\text { das sociedades } \\
\text { (BERDOULAY, 2017, p. } \\
\text { 170-171) }\end{array}$ & $\begin{array}{l}\text { Durkheim (1858 - 1917) num } \\
\text { primeiro momento e, em seguida, } \\
\text { os debates são resignificados por } \\
\text { Lucien Febvre (1878-1956), cujo } \\
\text { trabalho está na criação dos } \\
\text { Annales d'histoire économique et } \\
\text { sociale (depois Annales. } \\
\text { Économies, Sociétés, } \\
\text { Civilisations) }\end{array}$ & $\begin{array}{l}\text { Na Sociologia durkheimiana desenvolveu-se o } \\
\text { campo denominado "Morfologia Social", o qual } \\
\text { se opunha ao que considerava ser exagerado das } \\
\text { concepções de Friedrich Ratzel (1844 - 1904); } \\
\text { no lugar da proposta do "Determinismo } \\
\text { Ambiental" da Antropogeografia, sugeriu-se } \\
\text { considerar como secundária a influência } \\
\text { ambiental e estudar a organização social como } \\
\text { um sistema espacial autônomo, produto do } \\
\text { marco institucional e a consciência coletiva, } \\
\text { onde a dimensão social se explica por ela } \\
\text { própria; esta postura gerou correntes de } \\
\text { investigação divergentes e o afastamento entre } \\
\text { geógrafos e sociólogos e tentou subalternizar a } \\
\text { Geografia como simples ciência auxiliar da } \\
\text { História. }\end{array}$ \\
\hline $\begin{array}{l}\text { 8- Os Vidalianos - Paul } \\
\text { Vidal de La Blache e os seus } \\
\text { discípulos (BERDOULAY, } \\
\text { 2017, p. 171-178) }\end{array}$ & $\begin{array}{l}\text { Vidal da La Blache (1845-1918), } \\
\text { definitivamente a mais } \\
\text { proeminente } \\
\text { liderança política-acadêmica } \\
\text { da Escola Francesa de Geografia }\end{array}$ & $\begin{array}{l}\text { A constituição de uma enorme influência por } \\
\text { parte do grupo vidaliano tornou essa } \\
\text { perspectiva, que privilegiou a síntese regional, } \\
\text { decisiva na institucionalização do ensino e } \\
\text { pesquisa da ciência geográfica na França, com } \\
\text { reflexos de caráter mundial. }\end{array}$ \\
\hline
\end{tabular}

Fonte: Elaboração própria a partir de BERDOULAY (2017, p. 135-178).

No Capítulo 6, A Epistemologia Vidaliana (p. 179 - 227), expõe-se que durante sua vida, Vidal centralizava e influenciava as cátedras universitárias francesas. Após sua morte, seus discípulos mantiveram algumas propostas e modificaram outras. A identificação das regiões passou a ser um trabalho geográfico básico e, na busca da individualidade das regiões, além dos elementos da natureza, destacavam-se os aspectos culturais, atitude que aparentemente valorizava o que chamavam de Geografia Humana.

Entre as condições que permitiram o sucesso da perspectiva vidaliana constam um conjunto de tendências filosóficas que repercutiam na França no período de 1870 e 1914, que serão elementos decisivos para solidificar o corpo teórico do Possibilismo: 1 - as Ciências Sociais alcançaram um desenvolvimento considerável, ainda que sob a tutela teórica e metodológica do Naturalismo (com forte viés lamarckista); 2 - o espírito geográfico marcado pelas referências históricas, o Convencionalismo, a teoria da contingência e o Neokantismo. 
A herança de Immanuel Kant (1724 - 1804) é ressignificada para experiência que se desenvolve na França ocorre, sobretudo, por meio de Alfred Hettner (1859 - 1941), que será fundamental para a ênfase da diferenciação regional entre os vidalianos.

Lucien Febvre foi o responsável pela aplicação do termo Determinismo para a Geografia ratzeliana e Possibilismo (expressão jamais usada por Vidal) à Geografia lablacheana, criando uma polarização que não existia. Febvre, que defendia a interdisciplinaridade e a ampliação dos temas históricos, queria dialogar com seus compatriotas e fortalecer a Geografia de seu país em relação à Geografia Alemã. Assim tentou desmerecer a expressiva contribuição de Ratzel, valorizando os geógrafos compatriotas. Ao enfatizar a dimensão política, a Geografia praticada por Ratzel assemelhava-se à História Diplomática, Militar e Política, perspectiva hegemônica na França e que Febvre esforçava-se em combater. Em virtude de inúmeros debates configurados nos últimos anos, não se tem dúvida, de que a interpretação de Febvre é reducionista.

O Possibilismo não é facilmente sintetizado teoricamente. Ao contrário do que se pensa frequentemente, não é uma simples reação antiambientalista, limitando-se a negar o Determinismo Ambiental sobre a sociedade. Assim, não se trata de um "probabilismo", que, em última instância não seria mais do que uma versão atenuada do Determinismo Ambiental. As perspectivas concebidas por Vidal de La Blache e seus principais discípulos antes da Primera Guerra Mundial, constituem, de forma mais profunda numa verdadeira teoria geral das relações entre o ser humano e a natureza. Sua contribuição fundamental à ciência tem sido proporcionar um meio para superar as alternativas reducionistas dos determinismos, seja baseado na natureza, seja baseado na sociedade.

No capítulo 6, se apresenta a Conclusão (p.229 - 234), sublinha-se os fundamentos da moral na sua importância para a história do pensamento geográfico, num contexto de considerável mutação social do período analisado, repercutindo num conjunto muito diferenciado de abordagens no estudo do meio e do lugar que ocupa o ser humano.

No Post-Scriptum 2008 (p. 235 - 247) refere-se as transformações interpretativas ocorridas desde a primeira edição da obra (1981). Avalia-se que a mesma trouxe uma perspectiva inovadora ao analisar as interações reciprocas entre o contexto da sociedade e o pensamento geográfico, insistindo nas mediações (instituições, grupos de afinidade) que permitiam captar como se orientavam e como se estabilizavam os sistemas de ideias. Junto com essa abordagem contextual, mencionada no início, destacou-se a importância das narrativas e das descrições na constituição de uma linguagem discursiva da Geografia, tanto no auge da inflluência francesa quanto nos dias atuais. Acrsscente-se também a importância da síntese regional como um trunfo da contribuição vidaliana, que marca definitivamente suas conrrtribuições a ciência geográfica. 


\section{CONSIDERAÇÕES FINAIS}

Contrariando críticos da Escola Francesa de Geografia, Berdoulay argumenta, com sucesso, que essa corrente epistemológica ultrapassou em muito as supostas restrições do método descritivo, que se tornou uma verdadeira referência na História do Pensamento Geográfico convencional e reducionista.

Com todas as qualificações para se tornar uma referência também na tradução em língua portuguesa, essa obra conta com um Índice de nomes (p.249 - 255), que facilita muito a utilização da obra.

Tal como o trabalho de Haesbaert, Pereira e Ribeiro (Vidal, Vidais. Textos de geografia humana, regional e política, 2012), a tradução da obra de Berdoulay situa-se entre as obras de valor inestimável para as pesquisas acerca do pensamento geográfico.

\section{REFERÊNCIAS}

BERDOULAY, V. A abordagem contextual. Espaço e Cultura, Rio de Janeiro, n. 16, p. 47-56, 2003.

HAESBAERT, R.; PEREIRA, S. N.; RIBEIRO, G. Vidal, Vidais. Textos de geografia humana, regional e política. 1. ed. Rio de Janeiro: Bertrand Brasil, 2012. 464p.

JOHNSTON, R. J. Geografia e Geógrafos: a geografia humana anglo-americana desde 1945. Tradução de Oswaldo Bueno Amorim Filho. 1. ed. São Paulo: DIFEL, 1986. 359p. 